\title{
Rat Hepatoma BRL Cells Proliferation by Acrylamide and Alcohol Combination
}

\author{
Xiaoyun Shan ${ }^{1,2}$, Pengqi Wang ${ }^{3}$, Qing Feng ${ }^{2, *}$ \\ ${ }^{1}$ School of Public Health, University of South China, Hengyang, China \\ ${ }^{2}$ Department of Nutrition and Food Hygiene, Nanjing Medical University, Nanjing, China \\ ${ }^{3}$ Lianyungang Health Inspection Bureau, Lianyungang, China
}

Email address:

qingfeng@njmu.edu.cn (Qing Feng), shanxiaoyun0924@163.com (Xiaoyun Shan)

${ }^{*}$ Corresponding author

\section{To cite this article:}

Xiaoyun Shan, Pengqi Wang, Qing Feng. Rat Hepatoma BRL Cells Proliferation by Acrylamide and Alcohol Combination. International Journal of Nutrition and Food Sciences. Vol. 9, No. 3, 2020, pp. 78-85. doi: 10.11648/j.ijnfs.20200903.12

Received: May 14, 2020; Accepted: June 9, 2020; Published: June 23, 2020

\begin{abstract}
Acrylamide, exists in carbohydrate-rich food heated at high temperatures, is a probable carcinogen to humans. Excessive alcohol intake can also lead to a variety of pathological changes in the body. Acrylamide in the foods and alcohol in the drinks are unavoidable. And studies have demonstrated that combination of the two substances which are taken into the body via diet may cause adverse effects in the cells, even induce impairments on testicular spermatogenesis in male offsprings. Both acrylamide and alcohol are mainly metabolized in the liver, where cytochrome P450 2E1 (CYP2E1) acts as the common metabolic enzyme of the two xenobiotics. This study aimed to explore the effects of acrylamide and alcohol combination on rat hepatoma BRL cells proliferation and the probable mechanisms. MTT, western blotting, EdU fluorescence staining, flow cytometry and PCR were used. Results showed that combination of acrylamide and alcohol at low doses promoted BRL cells proliferation through CYP2E1/Akt/ NF-kB/cyclinB1/cyclinD1 activation and ROS production. The combined effects of acrylamide and alcohol largely depended on ROS level. Furthermore, acrylamide and alcohol could synergistically induce miR-21, which was related to the progress of liver regeneration. These data showed that combination of acrylamide and alcohol at low doses promoted BRL cells proliferation through inducing ROS production, which indicated that intake of fried starch food with small dose of alcohol might have positive effects on liver regeneration.
\end{abstract}

Keywords: Acrylamide, Alcohol, Proliferation, ROS, miR-21

\section{Introduction}

Acrylamide is a kind of water-soluble vinyl monomer formed from the hydration of acrylonitrile [1]. It has widespread application in many areas, such as drinking water purification, municipal sewage and industrial wastewater treatment, cosmetics and daily-use chemical additives, and laboratory reagents. Besides drinking water, people can also be exposed to a small amount of acrylamide from heating starchy foods (such as French fries, roasted coffee and bread, etc.) [2]. Due to its strong permeability, acrylamide can enter into the body through the digestive tract, respiratory tract, skin and mucous membrane quickly, with the fastest absorption in the gastrointestinal tract $[3,4]$. Because of the various toxic effects such as nerve, reproductive and genetic toxicity and carcinogenicity [5], acrylamide has caused extensive concern. Acrylamide metabolism in human and animal body is mainly through two competing ways: one is conjugating with reduced glutathione (GSH); another is generating epoxidation metabolites glycidamide by cytochrome P450 system, mainly CYP2E1, further conjugating with reduced GSH [6].

Moreover, in human daily activities, exposing to other environmental risk factors through respiratory tract, digestive tract and skin is inevitable as well. And, most of these factors act on the human body not by oneself. Thus, to study the toxicological effects of one poison, we should also consider its joint action with other materials. In recent years, with increasing consumption of alcohol, liver damage caused by alcohol is also on the rise year by year. Although 
some studies indicate that light to moderate alcohol consumption is associated with a reduced risk of multiple cardiovascular outcomes $[7,8]$, the potential harm still cannot be ignored.

It is noteworthy that alcoholic beverages drinking could also accompany the intake of other foods, such as potato chips, popcorn and fried chicken, which contain acrylamide. Exposing to the two kinds of potentially toxic substances together may cause more severe toxic effects on the body, which has raised the attention of experts and society as well. One study by Sen E et al through evaluating sexual development in male mice after intake of $14 \mathrm{mg} / \mathrm{kg}$ acrylamide and $2 \mathrm{~g} / \mathrm{kg}$ alcohol from gestation day 6 to postnatal day 21 suggests that consumption of acrylamide together with alcohol may induce impairments on testicular spermatogenesis in male offsprings, such as reduced gonadosomatic index of male offsprings and increased lipid peroxidation level and superoxide dismutase enzyme activity [9].

Based on our previous study, which showed that low doses of acrylamide could accelerate the hepatocellular carcinoma cells malignant proliferation [10], this subject aimed to study the effects of low dose of acrylamide and low dose of alcohol, alone or in combination, on normal liver cell proliferation, and expected to get the based data about the effects of a small amount of alcohol and dietary acrylamide together on liver regeneration.

\section{Materials and Methods}

\subsection{Cell Culture and Reagents}

BRL cells were purchased from Cell Centre of Chinese Academy of Medical Sciences (Peking, China). Cells were cultured in Dulbecco's Modified Eagle Medium (DMEM, Gibco, USA) supplemented with $10 \%$ fetal bovine serum (Gibco, Grand Island, NY), penicillin (100 units/mL, Gibco), and streptomycin $(100 \mu \mathrm{g} / \mathrm{mL}$, Gibco). These cells were maintained at $37{ }^{\circ} \mathrm{C}$ in a humidified atmosphere of $5 \% \mathrm{CO}_{2}$. Acrylamide (purity $>99.5 \%$, dissolved in $\mathrm{ddH}_{2} \mathrm{O}$ in a concentration of $1000 \mathrm{mM} / \mathrm{L}$ ) was purchased from Sigma-Aldrich (St Louis, MO, USA). Alcohol (purity > 99.7\%) was purchased from Sinopharm Chemical Reagent Co., Ltd (Shanghai, China).

\subsection{MTT Assay}

Cell viability was assessed by the methyl thiazol tetrazolium bromide (MTT) assay. Cells were seeded in a 96-well plate at a density of $4 \times 10^{3}$ cells per well in a final volume of $180 \mu \mathrm{L}$ of medium. After indicated treatment, the cells were incubated with MTT solution $(5 \mathrm{mg} / \mathrm{mL})$ at $37{ }^{\circ} \mathrm{C}$ for $4 \mathrm{~h}$. The formed formazan crystals were dissolved in DMSO at room temperate for 10 minutes. Then the absorbance was read at $490 \mathrm{~nm}$ with a microplate reader (Tecan /Infinite M200, Switzerland).

\subsection{Western Blot Analysis}

The experiments were prepared from seeding with $5 \times 10^{5}$ cells. After indicated treatments, the cells were washed twice with PBS and suspended in a lysis buffer including $1 \mathrm{mM}$ DTT, $0.1 \%$ protease inhibitor and $5 \mathrm{mM}$ PMSF (KeyGEN BioTECH, China). Protein concentrations were measured by BCA Protein Assay Kit (Beyotime, China). Sodium dodecyl sulfate (SDS)-polyacrylamide gel electrophoresis (PAGE) was used to separate $60 \mu \mathrm{g}$ of protein, which was then transferred to PVDF membrane (Millipore Corporation, USA) The primary antibodies included rabbit anti-NF- $\mathrm{KB} / \mathrm{p} 65$ monoclonal antibody (Cell Signaling technology, USA), rabbit anti-p-Akt monoclonal antibody (Cell Signaling technology, USA), rabbit anti-CYP2E1 monoclonal antibody (Epitomics, USA), mouse anti-Nrf2 monoclonal antibody (Cell Signaling technology, USA) and mouse anti- $\beta$-actin monoclonal antibody (BOSTER, China). Second antibodies included HRP-Conjugated AffiniPure Goat Anti-rabbit IgG (ZSGB-BIO, China) and HRP-Conjugated AffiniPure Goat Anti-mouse IgG (ZSGB-BIO, China). Immunoreactive proteins were visualized using ECL Western blotting detection reagents (GE Health-care, Buckinghamshire, UK). The bands were quantified with the Image $\mathbf{J}$ software.

\subsection{EdU Fluorescence Staining}

The 5-ethynyl-2'-deoxyuridine (EdU) fluorescence staining was used to detect the newly synthesized DNA in BRL cells (seeding with $4 \times 10^{3}$ cells per well in a 96-well plate) after the indicated treatment. All steps performed following the manufacturer's instructions of Cell-LightTM EdU DNA Cell Proliferation Kit (RiboBio, Guangzhou, China).

\section{5. siRNA Transfection}

BRL cells $\left(2.5 \times 10^{5}\right)$ were transfected with predesigned human CYP2E1 siRNA or siRNA control $(50 \mathrm{nM})$ (RiboBio, Guangzhou, China) in a six-well plate or a 96-well plate for $4 \mathrm{~h}$ with Lipofectamine 2000 reagent (Invitrogen, Carlsbad, Calif, USA) in a serum-free and antibiotic-free media. All steps performed following the manufacturer's instructions.

\subsection{Flow Cytometry Assay}

DCFH-DA fluorescent labeling was used to measure intracellular production of the reactive oxygen species (ROS) in BRL cells (seeded with $2.5 \times 10^{5}$ ). After the indicated treatment, the cell supernatants were removed and 2', 7'-dichlorofluorescin-diacetate (DCFH-DA) was added into each group. After incubation with DCFH-DA for 20 min at $37^{\circ} \mathrm{C}$, the cells were washed twice with PBS and maintained in $600 \mu \mathrm{L}$ PBS. The fluorescence images were captured by a fluorescence microscope (OLYMPUS U-RFLT50, Japan), under $\times 200$ magnification with the filter which excitation at $470-490 \mathrm{~nm}$ and emission at 510 $550 \mathrm{~nm}$.

\subsection{Real-Time Polymerase Chain Reaction}

Total RNA was extracted by the RNAiso Plus (TaKaRa 
BioTechnology, Dalian, China) following the manufacturer's protocol. For miRNA quantitative analysis, total RNA was reversely transcribed using the PrimeScriptTM RT Master Mix (TaKaRa BioTechnology, Dalian, China), and qPCR was performed using SYBRR Premix Ex TaqTMII (TaKaRa BioTechnology, Dalian, China). The miRNA primers were purchased from RiboBio Co., Ltd. (Guangzhou, Guangdong, China). All qPCR was performed with the Applied Biosystems 7300 Real Time PCR System (Applied Biosystems, Foster City, CA) according to manufacturer's instructions. Expression of miRNA was defined from the threshold cycle, and relative expression levels were calculated using the $2-\mathrm{Ct}$ method after normalization with reference to the expression of U6 small nuclear RNA.

\subsection{Statistical Analyses}

The results were presented as the mean \pm standard deviation (SD) compared with the controls. A one-way analysis of variance (ANOVA), which was followed by a Tukey HSD test for the multiple comparisons, was used to detect the differential effects of acrylamide and alcohol on BRL cells. A $P$ value $<0.01$ was considered statistically significant.

\section{Results}

\subsection{Synergistic Collaborative Effect of Low Doses of Acrylamide and Alcohol on BRL Cells Proliferation}

After treating BRL cells for 24 hours with different concentrations of acrylamide or alcohol, MTT assay was performed to detect cell viability. As the results shown in Figure 1a, acrylamide at less than $1000 \mu \mathrm{M}$ had no significant effect on cell activity. In the same way, only the alcohol reaching at $100 \mathrm{mM}$ or higher produced cytotoxic effect (Figure 1b). Then, we chose the acrylamide $(50,80,100 \mu \mathrm{M})$ and alcohol $(1,5,10 \mathrm{mM})$ doses, which acted no significant effects, for their combined experiment, finding that each group of the combination was able to promote the BRL cells survival. In the group co-treated with $100 \mu \mathrm{M}$ acrylamide and $10 \mathrm{mM}$ alcohol, the cell activity increase was most pronounced (Figure 1c).

In order to further validate the combined effects on cell proliferation of acrylamide and alcohol, EdU fluorescence staining assay was performed to detect the newly synthesized DNA in BRL cells. The results showed that EdU positive cells in the acrylamide and alcohol treated separately group after 24 $\mathrm{h}$ had no significant difference compared with the controls, while the combined treating group increased markedly (Figure 1d). These results suggested that acrylamide and alcohol combination could activate the DNA replication activity. (b)

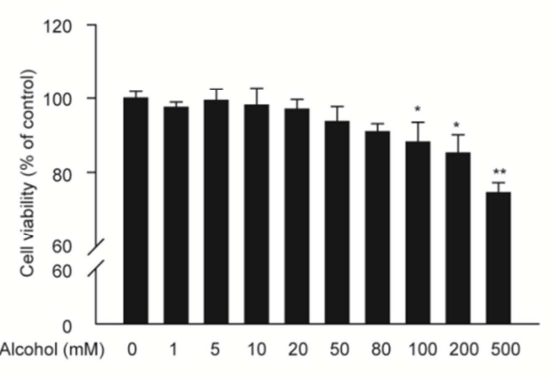

(d)

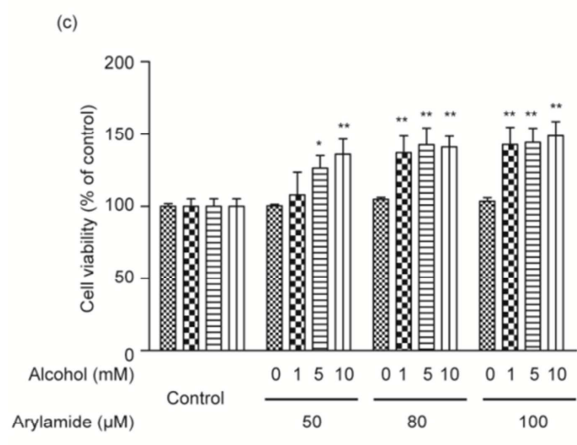

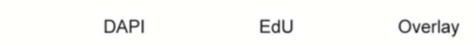

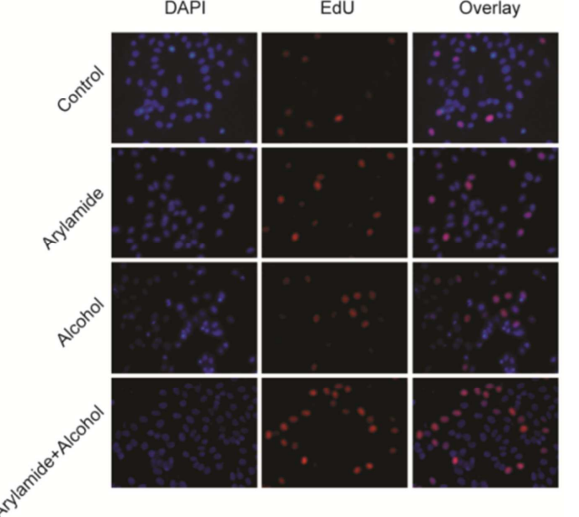

Figure 1. Effect of acrylamide and alcohol on proliferation of BRL cells.

Up to $2000 \mu \mathrm{M}$, acrylamide distinctly inhibited the viability of BRL cells after $24 \mathrm{~h}$ of treatment, as analyzed by MTT assay; Likely, alcohol showed no significant cytotoxicity on BRL below $100 \mathrm{mM}$ (a and b). Low doses of acylamide and alcohol combination largely increased BRL cells viability, especially at $100 \mu \mathrm{M}$ and $10 \mathrm{mM}$ respectively (c). The EdU-positive cells (red fluorescence staining) increased distinctly after co-treatment acrylamide (100 $\mu \mathrm{M}$ ) and alcohol $(10 \mathrm{mM})$ for $24 \mathrm{~h}$ measured by EdU fluorescence staining assay (d). Results are presented as the mean $\pm \mathrm{SD}$ from three independent experiments (in triplicate for each experiment). Statistical differences to the controls are shown as $* \mathrm{P}<0.01$, and $* * \mathrm{P}<0.001$. 


\subsection{Acrylamide and Alcohol Induced Cell Cycle Protein Increasing}

In this study, after 24 hours of treatment with $100 \mu \mathrm{M}$ of acrylamide and $10 \mathrm{mM}$ of alcohol, cyclinD1 and cyclinB1 raised in BRL cells (Figure 2a). Then, the cell cycle proteins

$$
\text { (a) }
$$

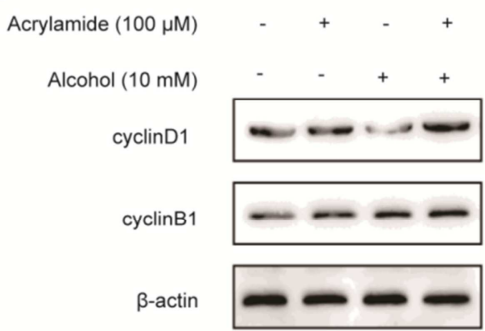

were measured at different time points and increased in a time-dependent way. But when reaching to $36 \mathrm{~h}$, they returned to normal (Figure $2 \mathrm{~b}$ ). These results suggested that low doses of acrylamide and alcohol can increase the expression of cyclinD1 and cyclinB1.

(b)

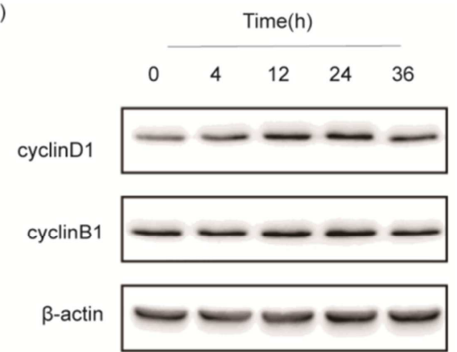

Figure 2. Effect of acrylamide and alcohol combination on cyclinD1 and cyclinB1 expressions.

Acylamide and alcohol combination largely increased cyclinD1 and cyclinB1 expressions in BRL cells (a). Acylamide and alcohol combination showed obvious effects on upregulation of cyclinD1 and cyclinB1 for 12 and $24 \mathrm{~h}$ treatment, but not for 4 and $36 \mathrm{~h}$ (b).

(a)

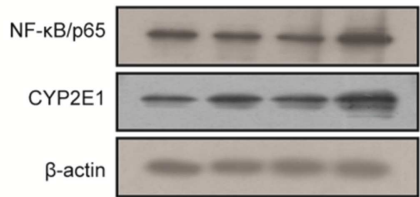

Acrylamide $(100 \mu \mathrm{M})$

Alcohol $(10 \mathrm{mM})$

(c)

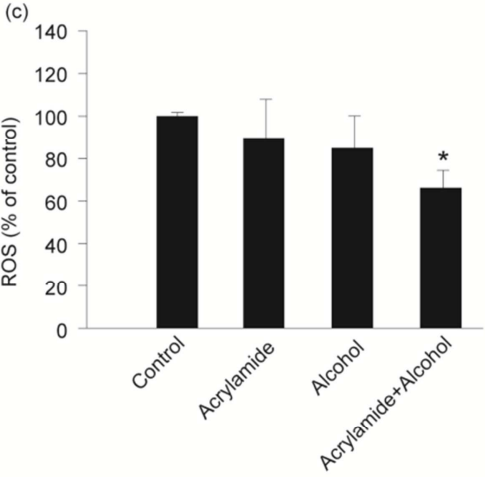

(e)

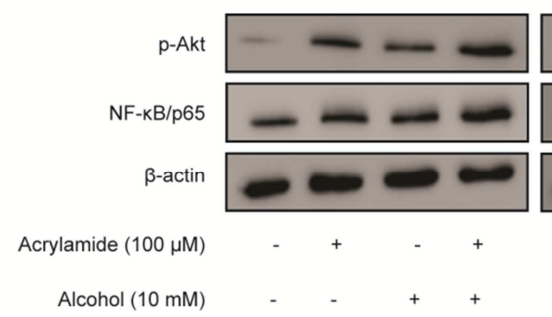

(b)

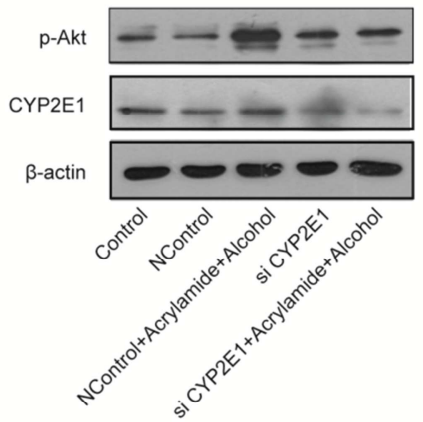

(d)

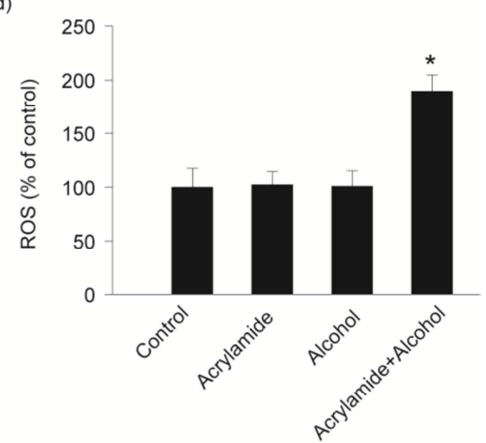

$12 \mathrm{~h}$

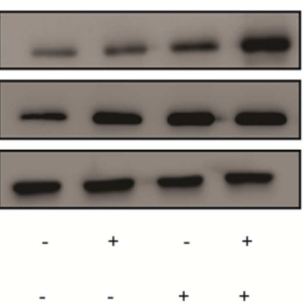

$36 \mathrm{~h}$

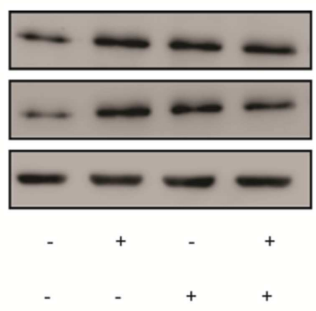

Figure 3. Effect of acrylamide and alcohol combination on ROS.

Acylamide and alcohol combination significantly induced NF- $\kappa$ B/p65, p-Akt and CYP2E1 expressions in BRL cells. And knockdown of CYP2E1 could prevent acylamide and alcohol combination to induce p-Akt ( $\mathrm{a}$ and b). Co-treatment for $24 \mathrm{~h}$ was able to induce production of ROS, but not for $4 \mathrm{~h}$ (c). Though co-treatments for different time periods all increased NF- $\mathrm{BB} / \mathrm{p} 65$ and p-Akt expressions, once reaching to $36 \mathrm{~h}$, the effect weakened (d). Results are presented as the mean $\pm \mathrm{SD}$ from three independent experiments (in triplicate for each experiment). Statistical differences to the controls are shown as $* \mathrm{P}<0.01$, and $* * \mathrm{P}<$ 0.001 . 


\subsection{Acrylamide and Alcohol Combination Could Induce Cellular ROS}

CYP2E1 is one of the main metabolic enzymes in the liver. Previous studies indicated that acrylamide or high doses of alcohol can induce CYP2E1 expression [10]. In this study, we treated BRL cells alone or in combination with acrylamide and alcohol for $24 \mathrm{~h}$. Though individual treatment did not induce CYP2E1 expression, the combined group significantly raised CYP2E1, which suggested that acrylamide and alcohol had an important synergy on CYP2E1 (Figure 3a). In addition, the proteins related to oxidative stress, such as Akt and NF- $\mathrm{BB}$, were both phosphorylated in the combined treating group. As shown in Figure $3 \mathrm{a}$ and Figure $3 \mathrm{~b}, \mathrm{NF}-\mathrm{\kappa B} / \mathrm{p} 65$ and $\mathrm{p}-\mathrm{Akt}$ expression were much higher than the controls. However, once CYP2E1 was knocked down, the co-treatment was not able to phosphate Akt anymore. As CYP2E1 can control the $\mathrm{NF}-\kappa \mathrm{B} / \mathrm{p} 65$ expression [10] and cell proliferation is able to be mediated by the activation of $\mathrm{NF}-\kappa \mathrm{B}$ via PI3K/Akt pathway [11], which means that acrylamide and alcohol might adjust cell proliferation through the molecular way as CYP2E1/Akt/ $\mathrm{NF}-\kappa \mathrm{B} /$ cyclinB1/cyclinD1. Studies have confirmed that moderate ROS is necessary for liver regeneration, as ROS at too low or too high levels can destroy the oxidation/antioxidant balance and inhibit the liver

(a)

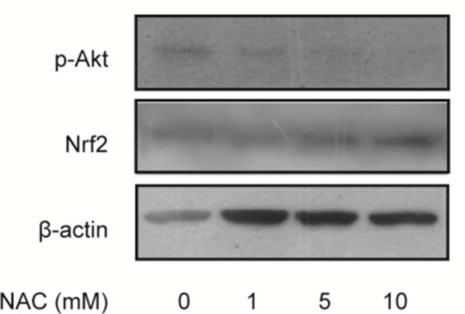

(c)

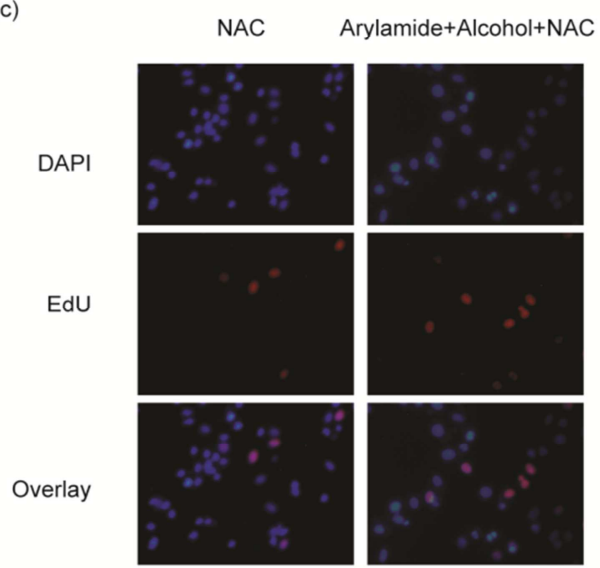

proliferation and regeneration [12]. We tested the level of ROS in cells after treatment for $24 \mathrm{~h}$, finding that the joint group had a marked increase in the level of ROS (Figure 3d). In addition, several REDOX proteins expression at other various time points such as 4,12 and $36 \mathrm{~h}$ was detected. After 4 and $12 \mathrm{~h}$, both $\mathrm{p}-$ Akt and NF- $\mathrm{kB} / \mathrm{p} 65$ was raised obviously, and the antioxidant Nrf2 was significantly lower after $12 \mathrm{~h}$ (delete this sentence). To $36 \mathrm{~h}$, various protein levels turned back to normal level again (Figure $3 \mathrm{e}$ ).

\subsection{BRL Cells Activity Enhancement by Combination of the Acrylamide and Alcohol Depended on REDOX Level}

In this study, acrylamide and alcohol combination obviously increased the number of BRL cells and cells were highly stretched after $24 \mathrm{~h}$. Once the antioxidant $\mathrm{N}$-acetyl-L-cysteine (NAC) was pretreated to cells, the expression of $\mathrm{p}$ - Akt and Nrf2 (antioxidant) changed. As collaboration effect was antagonized by NAC, acrylamide and alcohol could not increase $\mathrm{p}$ - Akt and decrease Nrf2 any more (Figure $4 \mathrm{a}$ and $4 \mathrm{~b}$ ). The cell proliferation was also inhibited (Figure 4c). These indicated that BRL cells activity enhancement by combination of the acrylamide and alcohol largely depended on cell oxidation level.

(b)

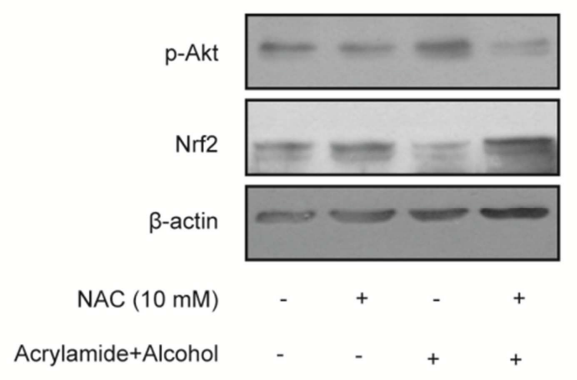

Figure 4. Antagonistic effects of NAC on acrylamide and alcohol combination in BRL cells.

NAC from 1 to $10 \mathrm{mM}$ could regulated the levels of NF- $\kappa \mathrm{B} / \mathrm{p} 65$ and p-Akt effectively in BRL cells (a). Pretreatment of NAC for $2 \mathrm{~h}$, acylamide and alcohol combination lost the ability to induce NF- $\mathrm{B} / \mathrm{p} 65$, p-Akt and proliferation in BRL cells (b and c). 


\subsection{Combination Treatment of Low Doses of Acrylamide and Alcohol Induced miR - 21 Expression in BRL Cells}

As one of the earliest discovered tiny RNA, miR-21 has been linked to regulation of cell proliferation, migration, and apoptosis of tumor process including liver cancer, lung cancer, breast cancer and prostate cancer and other tumors [13]. Several studies have documented the significant induction of miR-21 in the mouse liver during the proliferative phase of liver regeneration after partial hepatectomy [14, 15]. A study from Li J J showed that miR-21 could obviously upregulated and promoted BRL-3A cell proliferation, which involved in rat liver regeneration induced by partial hepatectomy [16]. Mentioned above, combination of alcohol and acrylamide could promote rat liver BRL cells proliferation, we examined the expression of miR-21 in BRL cells at different treating times. As shown in Figure 5, combined treatment raised miR-21 expression independently.

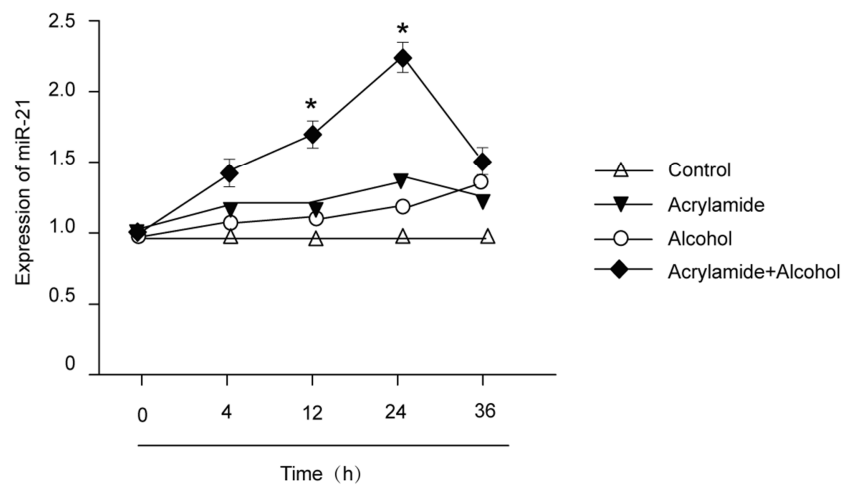

Figure 5. Effect of acrylamide and alcohol combination on miR-21 in BRL cells.

Acylamide and alcohol combination induced miR-21 in BRL cells after 12 and $24 \mathrm{~h}$ treatment. Results are presented as the mean \pm SD from three independent experiments (in triplicate for each experiment). Statistical differences to the controls are shown as $* \mathrm{P}<0.01$, and $* * \mathrm{P}<0.001$.

\section{Discussion}

Cell proliferation acts a very important role in organism growth, development, reproduction and genetic basis. However, cell proliferation is not always a good thing, especially for these people with cancer. On the one hand, unlimited proliferation makes the patient's body consuming large nutrients. On the other hand, a variety of toxins release and cancer cells transfer throughout the body, inducing a series of symptoms, such as weight loss, weakness, anemia, fever, impaired viscera function and even death. Initiation, proliferation and termination compose the liver regeneration process. Some signaling pathways/proteins like NF- $\kappa \mathrm{B}$ and miR-21 have been found involved in the process [14]. The induction of NF- $\kappa B$ and reduction of $\mathrm{P} 450$ activity can also be initiated by augmenter of liver regeneration (ALR) treatment [17].

Simultaneous consumption of acrylamide-containing foods and alcoholic beverages is inevitable. Studies have shown a higher genotoxic potential of alcohol/acrylamide combination treatment compared to acrylamide treatment alone in HepG2 cells. But the treating concentration is much higher (alcohol $(15-240 \mathrm{mM})$ and acrylamide $(5 \mathrm{mM}))$ [18]. To understand the effect of low dose of alcohol/acrylamide combination, we examined the change of BRL cell proliferation and the possible mechanism. In this study, the results conformed the promoting effects on BRL cells proliferation of low dose of acrylamide and alcohol combination from different respects, such as cell cycle, ROS level and miR-21 expression.

Cell cycle regulation plays a key role in cell growth process. CyclinD1 and cyclinB1 are two common cell cycle proteins which drive cells proliferation at cycle G1/S and G2/M, respectively [19]. When cells were treated with acrylamide and alcohol for different time periods, both cyclinD1 and cyclinB1 over expressed except for $36 \mathrm{~h}$. These indicated that acrylamide and alcohol function had strong timeliness.

The regulation of cell proliferation by ROS exists a lot of controversy. On one hand, ROS act as a proliferation promoting factor and increase both normal and cancer cells proliferation [20]. On the other hand, ROS level has a negative correlation to cell activity [21]. NAC, as a common antioxidant, can increase GSH content, remove oxygen free radicals and inhibit NF- $\mathrm{BB}$ activity and are widely used in clinical and experimental research in the field of respiratory, cardiovascular and nervous system as well as in AIDS [22]. In this study, low dose of acrylamide and alcohol increased the proliferation of the cells. Once the antioxidant NAC was pretreated, cell proliferation was inhibited. And we found that the cell proliferation induced by this combination depended on the ROS levels, indicating that acrylamide and alcohol could promote liver regeneration similar to liver resection and $\mathrm{H}_{2} \mathrm{O}_{2}$ treatment.

Liver regeneration is an important repair response to liver injury. But chronic ethanol consumption inhibits and delays liver regeneration in experimental animals. Moreover, upregulation of miR-21 following partial hepatectomy (PHx) is more robust in livers from ethanol-fed rats than in control rats, despite the inhibited cell proliferation, in apparent conflict with a pro-proliferative role of miR-21 in liver regeneration [23], which needs a comparative analysis of potential miR-21-affected functions during regeneration between naive and ethanol-adapted livers. However, in our study, low concentration of acrylamide and alcohol combination largely also facilitated the overexpression of miR-21 and cell proliferation.

In conclusion, high dose of acrylamide and alcohol together or alone was found to have genotoxicity, cytotoxicity and even carcinogenicity, but we showed that combination of low dose of acrylamide and alcohol could induce BRL cell proliferation through regulating cell cycle, ROS level and miR-21 expression. The data also proved that these functions dropped off after a certain time threshold. The results in this study applied in vitro model gave first hint of a possible benefit in liver regeneration entailed by simultaneous consumption of 
acrylamide-containing foods and alcoholic beverages. However, further studies are needed to act in rat models.

\section{Conclusion}

The present study showed that the combination of low doses of acrylamide and alcohol was able to promote BRL Cells proliferation through the molecular way as CYP2E1/Akt/ NF- $/ B /$ cyclinB1/cyclinD1. And the enhancement of BRL cells activity by combination of acrylamide and alcohol largely depended on cell oxidation level and raised miR-21 expression.

\section{Acknowledgements}

The study was funded by Scientific Research Project of Hunan Education Department (16C1389) and Science and Technology Project of Hengyang City (2015KS10).

\section{References}

[1] SMITH, E. A., OEHME, F. W. (1991). Acrylamide and polyacrylamide: a review of production, use, environmental fate and neurotoxicity. Rev Environ Health, 9: 215-228.

[2] IWONA C, CIESLIK, E., TOPOLSKA, K., SURMA, M.. (2019). Dietary acrylamide exposure from traditional food products in lesser poland and associated risk assessment. Annals of Agricultural \& Environmental Medicine Aaem.

[3] S RGEL, F., WEISSENBACHER, R., KINZIGSCHIPPERS, M., HOFMANN, A., ILLAUER, M., SKOTT, A., LANDERSDORFER, C. (2002). Acrylamide: increased concentrations in homemade food and first evidence of its variable absorption from food, variable metabolism and placental and breast milk transfer in humans. Chemotherapy, 48: 267 .

[4] SCHETTGEN, T., K TTING, B., HORNIG, M., BECKMANN, M. W., WEISS, T., DREXLER, H., ANGERER, J. (2004). Trans-placental exposure of neonates to acrylamide - a pilot study. International Archives of Occupational \& Environmental Health, 77: 213-216.

[5] EXON, J. H. (2006). A review of the toxicology of acrylamide. Journal of Toxicology \& Environmental Health Part B Critical Reviews, 9: 397-412.

[6] HUANG, Y. F., CHEN, M. L., LIOU, S. H., CHEN, M. F., UANG, S. N., WU, K. Y. (2011). Association of CYP2E1, GST and $\mathrm{mEH}$ genetic polymorphisms with urinary acrylamide metabolites in workers exposed to acrylamide. Toxicology Letters, 203: 118.

[7] RONKSLEY, P. E., BRIEN, S. E., TURNER, B. J., MUKAMAL, K. J., GHALI, W. A. (2011). Association of alcohol consumption with selected cardiovascular disease outcomes: a systematic review and meta-analysis. Bmj, 342: d671.

[8] BRIEN, S. E., RONKSLEY, P. E., TURNER, B. J., MUKAMAL, K. J., GHALI, W. A. (2011). Effect of alcohol consumption on biological markers associated with risk of coronary heart disease: systematic review and meta-analysis of interventional studies. Bmj, 342: 480-480.
[9] SEN, E., TUNALI, Y., ERKAN, M. (2015). Testicular development of male mice offsprings exposed to acrylamide and alcohol during the gestation and lactation period. Human \& Experimental Toxicology, 34: 401-14.

[10] SHAN, X. Y., LI, Y., MENG, X. L., WANG, P. Q., JIANG, P., FENG, Q. (2014). Curcumin and (-)-epigallocatechin-3-gallate attenuate acrylamide-induced proliferation in HepG2 cells. Food \& Chemical Toxicology An International Journal Published for the British Industrial Biological Research Association, 66: 194-202.

[11] SUN, H. Z., YANG, T. W., ZANG, W. J., WU, S. F. (2010). Dehydroepiandrosterone-induced proliferation of prostatic epithelial cell is mediated by NFKB via PI3K/AKT signaling pathway. Journal of Endocrinology, 204: 311-318.

[12] CHEN, T., LIU, J., DAI, D. (2014). Oxidative stress and liver regeneration. Chinese Journal of General Surgery.

[13] DIANA B. S., ARRIAGA. C., C., PEDROZA. T., A., I. A. DE L R., V., HERRERA, L., A. (2020). The promising role of mir-21 as a cancer biomarker and its importance in rna-based therapeutics.

[14] MARQUEZ, R. T., WENDLANDT, E., GALLE, C. S., KECK, K., MCCAFFREY, A. P. (2010). MicroRNA-21 is upregulated during the proliferative phase of liver regeneration, targets Pellino-1, and inhibits NF-kappaB signaling. American Journal of Physiology Gastrointestinal \& Liver Physiology, 298: 535-41.

[15] NG, R., SONG, G., ROLL, G. R. (2012). A microRNA-21 surge facilitates rapid cyclin D1 translation and cell cycle progression in mouse liver regeneration. Journal of Clinical Investigation, 122: 1097-108.

[16] LI, J. J., CHAN, W. H., LEUNG, W. Y., WANG, Y., XU, C. S. (2015). MicroRNA-21 promotes proliferation of rat hepatocyte BRL-3A by targeting FASLG. Genetics \& Molecular Research Gmr, 14: 4150-4160.

[17] WOLFGANG E, T. (2006). Repression of cytochrome P450 activity in human hepatocytes in vitro by a novel hepatotrophic factor, augmenter of liver regeneration. The Journal of pharmacology and experimental therapeutics, 2 .

[18] LAMY, E., V LKEL, Y., ROOS, P. H., KASSIE, F., MERSCH-SUNDERMANN, V. (2008). Ethanol enhanced the genotoxicity of acrylamide in human, metabolically competent HepG2 cells by CYP2E1 induction and glutathione depletion. International journal of hygiene and environmental health, 211: 74-81.

[19] SHI, X. M., ZHANG, G. J., CHANG, Z. S., WU, X. L. (2014). Viability Reduction of Melanoma Cells by Plasma Jet via Inducing G1/S and G2/M Cell Cycle Arrest and Cell Apoptosis. Plasma Science IEEE Transactions on, 42: 1640-1647.

[20] DAY, R. M., SUZUKI, Y. J. (2004). Cell proliferation, reactive oxygen and cellular glutathione. Dose Response, 3: 425-442.

[21] CARRERAS, M. C., CONVERSO, D. P., LORENTI, A. S. BARBICH, M., LEVISMAN, D. M., JAITOVICH, A., ANTICO ARCIUCH, V. G., GALLI, S., PODEROSO, J. J. (2004). Mitochondrial nitric oxide synthase drives redox signals for proliferation and quiescence in rat liver development. Hepatology, 40: 157-166.

[22] SAMUNI, Y., GOLDSTEIN, S., DEAN, O. M., BERK, M. (2013). The chemistry and biological activities of $\mathrm{N}$-acetylcysteine. Biochimica et biophysica acta, 1830: 4117. 
[23] DIPPOLD, R. P., VADIGEPALLI, R., GONYE, G. E., HOEK, J. B. (2012). Chronic ethanol feeding enhances miR-21 induction during liver regeneration while inhibiting proliferation in rats. American journal of physiology. Gastrointestinal and liver physiology, 303: 733-43. 